\title{
Psychometric properties of the perceived stress scale in Ethiopian university students
}

Md Dilshad Manzar ${ }^{1}$, Mohammed Salahuddin ${ }^{2 *}$, Sony Peter ${ }^{3}$, Ahmad Alghadir ${ }^{4}$, Shahnawaz Anwer ${ }^{4}$, Ahmed S. Bahammam ${ }^{5,6}$ and Seithikurippu R. Pandi-Perumal ${ }^{7}$

\begin{abstract}
Background: Stress is a common psychological condition usually associated with many psycho-physical disorders. Stress and its risk factors are frequently seen in Ethiopians including university students. In such circumstances, a valid measure to screen for stress in Ethiopians is necessary. Therefore, we assessed the psychometric properties of the Perceived Stress Scale (PSS) in Ethiopian university students.

Methods: A cross-sectional study with a simple random sampling method was performed on students of Mizan-Tepi University, Mizan-Aman, Ethiopia. The study presents a psychometric investigation on a sample of 387 students (age $=21.8 \pm 3.8$ years, and body mass index $=20.8 \pm 3.2 \mathrm{~kg} / \mathrm{m}^{2}$ ) who completed PSS, Generalized anxiety disorder-7 scale (GAD-7), and a socio-demographics tool. McDonald's Omega (internal consistency), factor validity for ordinal data and convergent validity (Spearman's correlation) were assessed.

Results: No ceiling/floor effect was seen for the total or factor scores of the PSS-10 and PSS-4. Two factor model of the PSS-10 was favored by fit indices with Comparative Fit Index $>0.95$, Weighted root mean square residual $<.05$ and root mean square error of approximation<.08. McDonald's Omega was 0.78 and 0.68 for the PSS-10: Factor-1 and PSS-10: Factor-2, respectively. McDonald's Omega was 0.70 and 0.54 for the PSS-4: Factor-1 and PSS-4: Factor-2, respectively. There were moderate-strong correlations $(r=0.62-0.83)$ between PSS factors and respective items loading on them. PSS scores were correlated with GAD-7 $(r=.27-.40, p<.01)$.
\end{abstract}

Conclusion: The psychometric measures support the validity of the PSS-10 in Ethiopian university students.

Keywords: PSS, Anxiety, Stress, Africa, Factor analysis, McDonald's omega

\section{Background}

Stress is the reaction when human perceives a discrepancy in his resources and/or the ability to respond to an event or stimulus or stressor [1]. Eventually, stress has been conceptualized into three perspectives: (i) biological, physiology of the stress stimulus and response; (ii) environmental, related to life events; and (iii) psychological, assessment of subjective stress and dealing methods [1, 2]. Psychological stress is associated with asthma, upper respiratory tract infections, smoking, depression, diabetes, epilepsy, HIV/AIDS, herpes viral infections, autoimmune diseases, wound healing, self-reported measures of health behavior and help-seeking [3-5].

\footnotetext{
* Correspondence: msalahuddin.mohammed@gmail.com

${ }^{2}$ Department of Pharmacy, College of Medicine and Health Sciences,

Mizan-Tepi University (Mizan Campus), Mizan-Aman, Ethiopia

Full list of author information is available at the end of the article
}

Perceived stress is a risk factor for poor sleep quality in Ethiopian university students [6]. Stress is common in various sections of the Ethiopian population such as university students [6], epilepsy patients [7], HIV-infected patients [8], nurses [9], and females students with childhood sexual abuse [10]. Moreover, many risk factors, i.e., substance use [11-13], sleep problems [6, 11, 12], HIV [14], food insecurity [15], poverty [15], and risky sexual behavior [14] for stress and related mental problems are commonly prevalent in Ethiopian populations. It can therefore arguably be considered that there is a prospect of the undiagnosed and under-recognized magnitude of stress in the Ethiopian population. Indeed, similar to most places, depression seems to be more researched in Ethiopia than stress and other related psychological problems. The preponderance of depression in Ethiopian psychometric research is evidenced by the availability of validated tools to measure

(c) The Author(s). 2019 Open Access This article is distributed under the terms of the Creative Commons Attribution 4.0 International License (http://creativecommons.org/licenses/by/4.0/), which permits unrestricted use, distribution, and 
depression in Ethiopians [16-19]. However, no tool has been validated in Ethiopians to assess stress.

Therefore, in this study, we examined the psychometric validation of one of the most widely used questionnaire tools to evaluate psychological stress, i.e., the Perceived Stress Scale $[2,20]$. This tool measures the extent and/or severity of self-reported appraisal of the stressors effect on respondent's life [20]. There are three versions; 14-item scale called PSS-14, 10-item scale in short PSS-10, and 4 -item scale called PSS-4 [3, 20]. The psychometric properties of the PSS have been assessed in various cultures across the globe, but have never been validated in Ethiopians. PSS has been translated into many languages and has been found to have adequate validity and reliability in various demographics of the population $[2,20]$. The convergent validity of the PSS has been evaluated by assessing correlation of the PSS scores with the measures of anxiety including the Generalized anxiety disorder-7 (GAD-7) scale and the Hospital Anxiety and Depression Scale (HADS) $[2,21]$. However, research is required to ascertain some aspects of the psychometric properties of the PSS. The items of the PSS are ordinal in nature; therefore, it would be better to investigate internal consistency using ordinal alpha or McDonald's Omega and factorial validity employing polychoric correlation matrix with estimation method suitable for ordinal data like robust diagonally weighted least squares (robust DWLS). However, most of the studies investigating the psychometric properties of the PSS employed the Cronbach's alpha [2]. Similarly, statistical discrepancies are evident in previous works like use of maximum likelihood estimation for factor analysis, which is more suitable for normally distributed continuous data [22, 23]. Furthermore, the psychometric properties of the PSS-4 are not well studied in the student population. Therefore, this study assessed the psychometric properties, i.e., ceiling/floor effect, factorial validity, internal consistency, item discrimination, and criterion validity like convergent validity, of PSS-10 and PSS-4 in Ethiopian university students. PSS-10 and PSS-4 are both brief measures but PSS- 4 is still shorter. If both PSS-10 and PSS-4 show similar psychometric properties then the use of PSS-4 may be favorable.

\section{Material and methods Participants}

Six hundred and thirty students were initially enrolled from Mizan-Tepi University, Mizan-Aman, Ethiopia for a psychological health survey (Fig. 1). Of these, 562 participated with a response rate of $89.21 \%$. From this, a sample of 400 students was randomly selected for this study (Fig. 1). Here we report the findings from a sample comprising of 387 students (age $=21.8 \pm 3.8$ years, and body mass index $=20.8 \pm 3.2 \mathrm{~kg} / \mathrm{m}^{2}$ ) after removing person-level missing values $(n=13)$. There were no construct-level or item-level missing values for PSS scores (Fig. 1). Psychometric properties were investigated in a sample $(n=386)$ after deleting

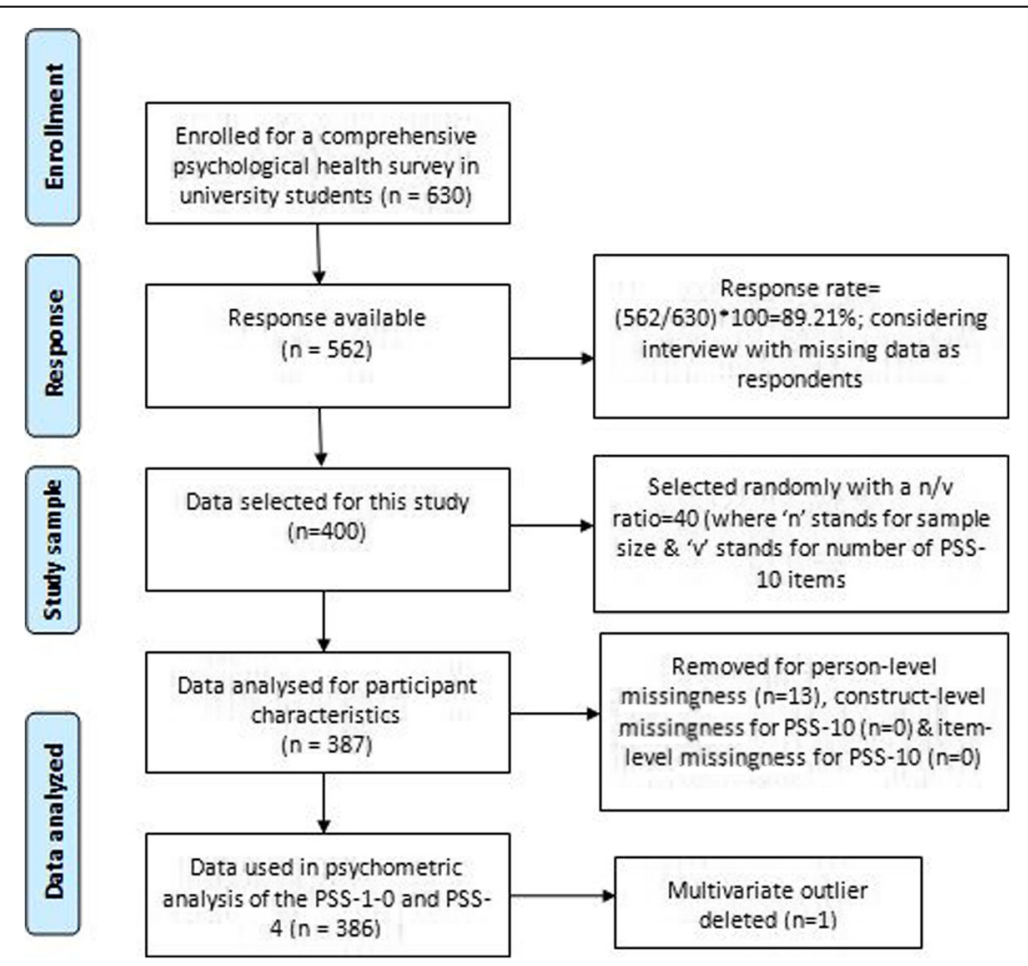

Fig. 1 Schematic of study sample 
multivariate outlier $(n=1)$ as determined by Mahalanobis distance $\left(\chi^{2}=29.59, \mathrm{df}(10), p<0.001\right)$ (Fig. 1).

\section{Procedure}

The study was approved by the institutional Ethical committee, College of Medicine and Health Sciences, Mizan-Tepi University, Ethiopia. This was a cross-sectional study with a simple random sampling design. All the participants were informed about the aim and the procedures of the study. Those with self-reported problems of memory and/or use of neuro-psychotic medications were excluded. The participants provided written informed consent. PSS-10, PSS-4, Generalized anxiety disorder-7 scale (GAD7 ), and a socio-demographics questionnaire were employed. Ethiopia is home to about eighty languages and students in the university belong to various linguistic ethnicities. Therefore, the study employed English versions of all the questionnaires.

\section{Measures}

\section{Perceived stress scale}

The PSS is a 10-item questionnaire to measure the self-reported level of stress in the respondents by assessing feelings and thoughts during the last month. Each item is scored from 0 (never) to 5 (very often) with a range of 0 to 40 for the total score of the scale. A higher level of stress is indicated by higher scores on this scale [20]. Six items of the PSS-10 measure stress and 4 items measure coping strategy to stress. The PSS-4 is a brief tool derived from the PSS-10 with 4 items, of which 2 items assess stress while 2 items measure coping strategy to stress [20].

\section{Generalized anxiety disorder - 7 scale}

The GAD-7 scale is a 7-item questionnaire to measure the self-reported level of anxiety in the respondents during the preceding two weeks. Each item is scored from 0 (not at all) to 4 (nearly every day). The scores of all items are added to get the total scores, with a range of 0 to 21 . The items were designed to quantify symptoms of anxiety according to the Diagnostic and Statistical Manual of Mental Disorders-IV-TR [24]. The GAD-7 has adequate psychometric validity, i.e., convergent validity, diagnostic validity, factorial validity, internal consistency, test-re-test reliability in various populations [25].

\section{Statistical analysis}

SPSS 23.0 with AMOS; which is an add-on module for SPSS along with a plug-in for AMOS and FACTOR version 10.8.04 were used for statistical analysis. Socio-demographics and item analysis were performed by descriptive statistics like frequency, mean with standard deviation, percentage, and Spearman's correlation between PSS Factor scores and item scores loading on them. Internal consistency was assessed by the McDonald's Omega. Item discrimination and convergent validity were evaluated by Spearman's correlation test.

Bartlett's test of Sphericity, communality, determinant and Kaiser-Meyer-Olkin test of sampling adequacy (KMO) were employed to assess sample size adequacy and sample suitability for factor analysis. Factor analysis was performed using FACTOR version 10.8.04 employing polychoric correlation matrix. Confirmatory factor analysis (CFA) was performed using the robust DWLS extraction with Promin rotation using bootstrap on previously validated models, i.e., both 2 -Factor and 1-Factor models for both PSS-10 and PSS-4 [2]. CFA was run on 4 models, i.e., 2 of PSS-10; 1-Factor model (Model-A), and 2-Factor model (Model-B) [22] and 2 models of PSS-4; 1-Factor model (Model-C) and 2-Factor model (Model-D). Multiple indices from different classes of fit measurements were employed [26]. Model fit was indicated by a robust mean and variance-adjusted Chi Square statistics (non-significant $p$ value), comparative Fit Index $(\mathrm{CFI}>0.95)$, Weighted root mean square residual (WRMR $<0.5)$ and root mean square error of approximation $(\mathrm{RMSEA}<0.8)$ [27].

\section{Results \\ Descriptive}

More than one third of the students reported no athletic activity. About $26 \%$ of students were either under-weight, over-weight or obese. 'B' was the most commonly reported grade at the last examination. Almost half of the students practiced Orthodox denomination of the Christianity. About one third of the students did not prefer to report their family's monthly income (Table 1). The average scores for the PSS and GAD-7 scale are shown in Table 1 . Nearly $5 \%$ of students reported the use of khat or alcohol (Table 1).

\section{Preliminary item analysis}

Item analysis for the PSS scores in the study participants is shown in Table 2. According to previous work, we scored ceiling or floor effect if more than $15 \%$ of respondents reported the highest or the lowest score, respectively $[11,28]$. Item-1, item-2, item-3, item-4, item-6, item-9 and item-10 showed floor effect; while none had ceiling effect (Table 2). However, there was no issue of ceiling/ floor effect for PSS-10 total, PSS-10: Factor-1, PSS-10: Factor-2, PSS-4 total, PSS-4: Factor-1 and PSS-4: Factor-2 scores (Table 2).

\section{Factorial validity}

\section{Sample adequacy and suitability for factor analysis}

The Kaiser-Meyer-Olkin Test of Sampling Adequacy (KMO) values were 0.83 and 0.54 , respectively for the PSS-10 and the PSS-4, which showed that the degree of common variance among PSS item scores was 
Table 1 Socio-demographics of Ethiopian university students

\begin{tabular}{|c|c|}
\hline Characteristics & $\begin{array}{l}\text { Mean } \pm \text { SD/ Frequency } \\
\text { (Percentage) }\end{array}$ \\
\hline Age (yr) & $21.8 \pm 3.8$ \\
\hline \multicolumn{2}{|l|}{ Attendance (\%) } \\
\hline Up to 80 & $49(12.7 \%)$ \\
\hline $80-90$ & $39(10.1 \%)$ \\
\hline $90-100$ & 299(77.3\%) \\
\hline \multicolumn{2}{|l|}{ Athletic activity (min/day) } \\
\hline No activity & $145(37.5 \%)$ \\
\hline Less than 60 & $51(13.2 \%)$ \\
\hline $60-120$ & 151(39\%) \\
\hline More than 120 & $40(10.3 \%)$ \\
\hline \multicolumn{2}{|l|}{$\mathrm{BMI}\left(\mathrm{Kg} / \mathrm{m}^{2}\right)$} \\
\hline Underweight & $66(17.1 \%)$ \\
\hline Normal & $286(73.9 \%)$ \\
\hline Overweight & $27(7.0 \%)$ \\
\hline Obese & $8(2.1 \%)$ \\
\hline \multicolumn{2}{|l|}{ Gender } \\
\hline Male & $321(82.9 \%)$ \\
\hline Female & $66(17.1 \%)$ \\
\hline \multicolumn{2}{|c|}{ Grade point average (at last semester examination) } \\
\hline C & $94(24.3 \%)$ \\
\hline $\mathrm{C}+$ & $43(11.1 \%)$ \\
\hline B- & $24(6.2 \%)$ \\
\hline B & $107(27.6 \%)$ \\
\hline $\mathrm{B}+$ & $58(15.0 \%)$ \\
\hline A- & $52(13.4 \%)$ \\
\hline $\mathrm{A} / \mathrm{A}+$ & $5(1.3 \%)$ \\
\hline Un-reported & $4(1.0 \%)$ \\
\hline \multicolumn{2}{|l|}{ Religion } \\
\hline \multicolumn{2}{|l|}{ Christianity } \\
\hline Catholic & $1(0.3 \%)$ \\
\hline Orthodox & $187(48.3 \%)$ \\
\hline Protestants & $122(31.5 \%)$ \\
\hline Islam & $68(17.8 \%)$ \\
\hline Others & $9(2.3 \%)$ \\
\hline \multicolumn{2}{|l|}{ Monthly Family Income (In Birr) } \\
\hline Very Low (less than 445) & $41(10.6 \%)$ \\
\hline Low (446-1200) & $67(17.3 \%)$ \\
\hline Average (1201-2500) & $53(13.7 \%)$ \\
\hline Above average (2501-3500) & $30(7.8 \%)$ \\
\hline High (greater than 3500) & $72(18.6 \%)$ \\
\hline Unknown & $124(32.0 \%)$ \\
\hline GAD-7 scale & $7.2 \pm 4.9$ \\
\hline
\end{tabular}

Table 1 Socio-demographics of Ethiopian university students (Continued)

\begin{tabular}{ll}
\hline Characteristics & $\begin{array}{l}\text { Mean } \pm \text { SD/ Frequency } \\
\text { (Percentage) }\end{array}$ \\
\hline PSS-10:Factor-1 & $10.72 \pm 4.74$ \\
PSS-10:Factor-2 & $7.35 \pm 3.25$ \\
PSS-10:total & $18.07 \pm 4.72$ \\
PSS-4: total & $7.14 \pm 2.43$ \\
Substance use & \\
Alcohol & \\
No & $364(94.1 \%)$ \\
Yes & $23(5.9 \%)$ \\
Chat Chewing & \\
No & $370(95.6 \%)$ \\
Yes & $17(4.4 \%)$ \\
Cigarette & \\
No & $385(99.5)$ \\
Yes & $2(0.5 \%)$
\end{tabular}

SD: Standard Deviation; BMI: Body mass index

GAD-7: Generalized Anxiety Disorder-7 scale

PSS: Perceived stress scale

meritorious for the PSS-10 but poor for PSS-4 [29]. The Bartlett's test $(<.001)$ imply that the original matrix is not an identity matrix, i.e., there is no problem of singularity in the measured variables-PSS item scores for both the PSS-10 and the PSS-4 [29]. The determinant score; PSS-10 (0.14) and PSS-4 (0.74), found that there was no issue of multi-collinearity in the PSS item scores [29]. The communality for all the PSS-10 item scores was above 0.2 (Table 2, Additional file 1), implying that proportion of variance explained by the common factors was adequate [30]. However, for the PSS-4, one of the items had a communality of 0.08 ( Table 2), suggesting that the proportion of variance explained by the common factors was not adequate for the PSS-4 [30].

\section{Confirmatory factor analysis}

PSS-10: model-B (Fig. 2) showed the best fit; highest value of the CFI (.989), lowest value of the RMSEA (.038) and optimum value of WRMR (.034) (Additional file 2, Table $3)$. Though, model-D, showed favorable values of fit indices but one of its items had very low communality (Fig. 2, Table 2-3).

\section{Internal consistency and item discrimination}

McDonald's Omega for the PSS-10: Factor-1 and the PSS-10: Factor-2 was 0.80 and 0.68 , respectively While, McDonald's Omega was 0.70 and 0.54 for the PSS-4: Factor-1 and the PSS-4: Factor-2, respectively. The item-Factor correlations for the PSS-10: Factor-1 $(r=$ $0.62-0.70, p<.01)$ and the PSS-10: Factor- $2(r=0.67-0.69$, 
Table 2 Descriptive statistics, item-Factor correlations, and Communality of the Perceived Stress Scale (PSS-10 \& PSS-4) in Ethiopian university students

\begin{tabular}{|c|c|c|c|c|c|c|c|c|c|c|c|}
\hline \multirow{3}{*}{$\begin{array}{l}\text { Perceived } \\
\text { Stress } \\
\text { Scale } \\
\text { items }\end{array}$} & \multicolumn{4}{|c|}{ Item-Factor score Correlation ${ }^{\#}$} & \multicolumn{2}{|c|}{ Communality } & \multicolumn{5}{|c|}{ Percentage distribution of Item scores } \\
\hline & \multicolumn{2}{|l|}{ PSS-10 } & \multicolumn{2}{|l|}{ PSS-4 } & \multirow{2}{*}{$\begin{array}{l}\text { PSS- } \\
10\end{array}$} & \multirow[t]{2}{*}{ PSS-4 } & \multirow[t]{2}{*}{0} & \multirow[t]{2}{*}{1} & \multirow[t]{2}{*}{2} & \multirow[t]{2}{*}{3} & \multirow[t]{2}{*}{4} \\
\hline & Factor-1 & Factor-2 & Factor-1 & Factor-2 & & & & & & & \\
\hline Item-1 & $.66^{*}$ & & & & .41 & & 21.0 & 17.9 & 40.2 & 12.7 & 8.3 \\
\hline Item-2 & $.70^{*}$ & & $.83^{*}$ & & .48 & .35 & 16.8 & 20.5 & 37.0 & 15.8 & 9.8 \\
\hline Item-3 & $.65^{*}$ & & & & .37 & & 19.4 & 18.7 & 36.3 & 17.4 & 8.3 \\
\hline Item-4 & & $.68^{*}$ & & $.83^{*}$ & .26 & .08 & 20.2 & 29.0 & 26.2 & 11.9 & 12.7 \\
\hline Item-5 & & $.67^{*}$ & & $.75^{*}$ & .38 & .20 & 9.1 & 25.6 & 38.1 & 16.6 & 10.6 \\
\hline Item-6 & $.62^{*}$ & & & & .32 & & 16.1 & 22.8 & 32.1 & 22.5 & 6.5 \\
\hline Item-7 & & $.69^{*}$ & & & .45 & & 14.2 & 31.1 & 32.1 & 13.0 & 9.6 \\
\hline Item-8 & & $.67^{*}$ & & & .35 & & 9.8 & 23.1 & 35.0 & 20.5 & 11.7 \\
\hline Item-9 & $.68^{*}$ & & & & .44 & & 16.1 & 15.0 & 39.1 & 19.2 & 10.6 \\
\hline Item-10 & $.66^{*}$ & & $.80^{*}$ & & .42 & .36 & 15.8 & 27.5 & 33.7 & 16.3 & 6.7 \\
\hline
\end{tabular}

${ }^{\#}$ Spearman's correlation coefficient

* $p<0.01$

Items of PSS-10: Item-1 to Item-10

Items of PSS-4: items-2, 4, 5 and 10

$p<.01)$ were moderate to strong (Table 2). The item-Factor correlations for the PSS-4: Factor-1 $(r=0.80-0.83, p<.01)$ and the PSS-4: Factor- $2(r=0.75-0.83, \mathrm{p}<.01)$ were strong (Table 2).

\section{Convergent validity: Correlation between GAD-7 and PSS scores}

The PSS-10 total score and the PSS-10: Factor-1 scores had a weak to moderate correlation $(r=0.34$ and $r=0.40$, $p<.01$ respectively) with the GAD-7 total score (Table 4 ). The PSS-4 total and the PSS-4: Factor- 1 scores had a weak to moderate correlation $(r=0.27$ and $r=0.38, \mathrm{p}<.01$, respectively) with the GAD-7 total score (Table 4).

\section{Discussion}

This is the first study to evaluate the psychometric validation measures of the PSS-10 and the PSS-4 in Ethiopian Africans in general and university students in particular. The investigation found sufficient level of the ceiling/floor effect, item discrimination, internal consistency, convergent validity, and factorial validity for PSS-10 in the study population.

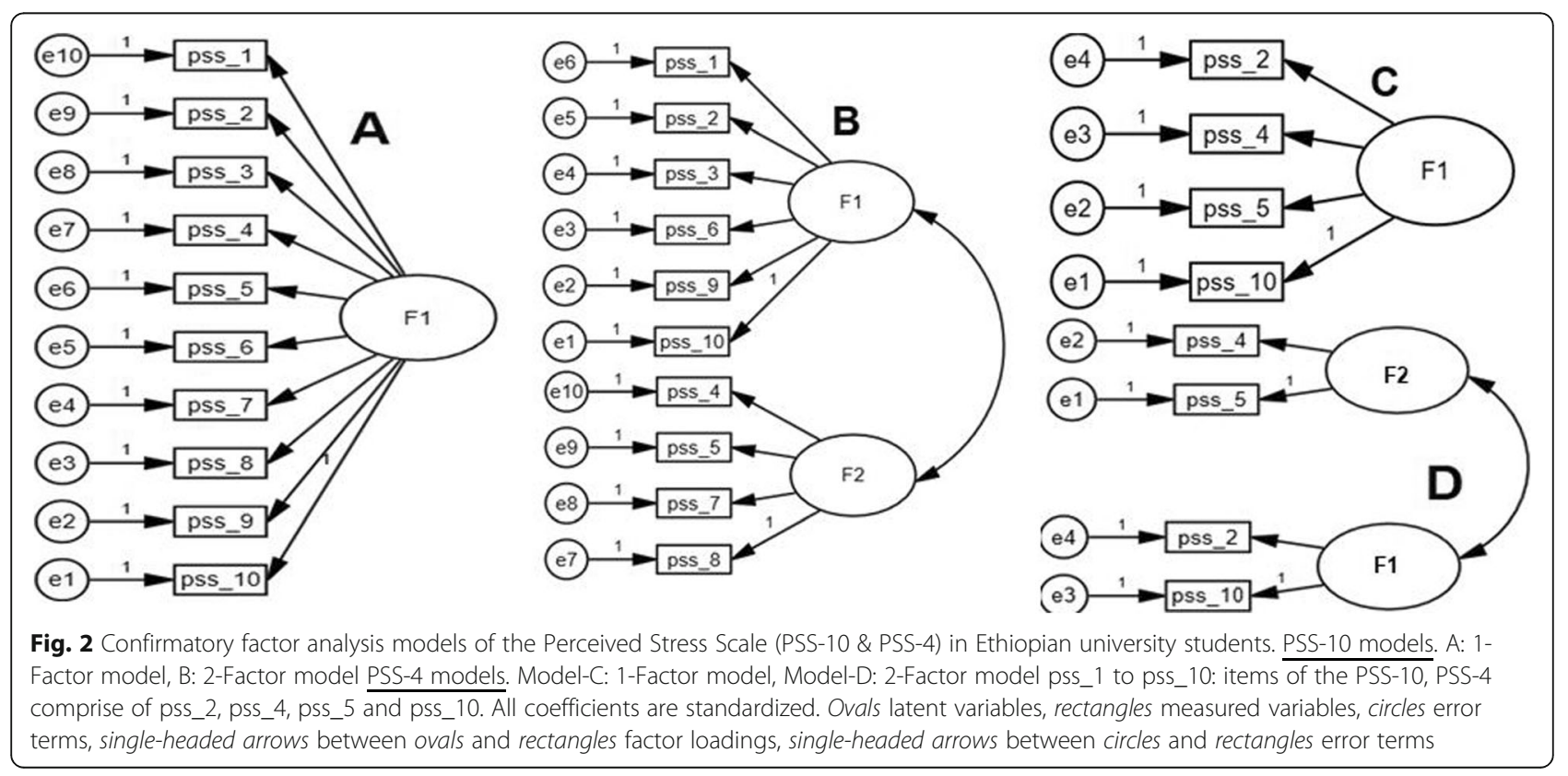


Table 3 Fit statistics of the Perceived Stress Scale (PSS-10 \& PSS-4) in Ethiopian university students

\begin{tabular}{clllllll}
\hline Models & CFI & WRMR & RMSEA & $X^{2 \#}$ & df & $p$ & $X^{2} / d f$ \\
\hline \multicolumn{1}{l}{ PSS-10 } & & & & & & & \\
A & .891 & .088 & $.102(.070-.123)$ & 175.459 & 35 & $<.001$ & 5.014 \\
B & .989 & .034 & $.038(.017-.046)$ & 40.235 & 26 & .037 & 1.548 \\
PSS-4 & & & & & & & \\
C & .723 & .100 & $.198(.122-.285)$ & 32.317 & 2 & $<.001$ & 16.158 \\
D & .976 & .000 & $.083(.000-.182)$ & 3.680 & 1 & .055 & 3.680
\end{tabular}

\#: Robust Mean and Variance-Adjusted Chi Square

CFI: Comparative Fit Index, WRMR: Weighted root mean square residual, RMSEA: root mean square error of approximation

PSS-10 models; A: 1-F model, B: 2-F model

PSS-4 models; C: 1-F model, D: 2-F model

\section{Preliminary item analysis}

The absence of both the floor and ceiling effects entails that even at the lowest or the highest scores of the PSS total and factor scores for both the PSS-10 and the PSS-4, the variance of the measurement is not unaccounted [28]. This favors the structural validity of the PSS-10 and the PSS-4 in Ethiopian university students as a self-reported measure of stress. Of the few previous studies that investigated this aspect of the validity of the PSS, Wu and Amtmann reported that there was no major floor and/or ceiling effects in Americans Multiple Sclerosis patients [31].

\section{Factorial validity}

CFA (Fig. 2 and Table 4) favored the 2-Factor model for the PSS-10 in the Ethiopian university students. Most of the previous studies have also favored the 2-Factor model of the PSS-10 and PSS-4 [2, 21, 32, 33]. However, some of the studies reported a bi-factor model [34] while some reported a 1-Factor model [2]. Similarly, previous works have validated a 2-Factor model for the PSS-10 among Americans, Thai and Turkish university students $[2,35]$. Incidentally, the 2-Factor structures of both the

Table 4 Criterion validity: Correlation of the Perceived Stress Scale with Generalized Anxiety Disorder-7 scale in Ethiopian university students

\begin{tabular}{ll}
\hline PSS scores & GAD-7 total \\
\hline $\begin{array}{l}\text { PSS-10 } \\
\text { Factor-1 }\end{array}$ & $.40^{* *}$ \\
Factor-2 & -.05 \\
PSS total & $.35^{* *}$ \\
PSS-4 & \\
\hline Factor-1 & $.38^{* *}$ \\
Factor-2 & -.01 \\
PSS total & $.27^{* *}$ \\
\hline
\end{tabular}

${ }^{*} p<0.05,{ }^{* *} p<0.01$

GAD-7: Generalized Anxiety Disorder-7 scale
PSS-10 and the PSS-4 are theoretically favored over a unidimensional model because some of the items measure stress, while others assesses the coping strategy to the stress [20].

\section{Internal consistency and item discrimination}

The internal consistency as assessed by the McDonald's Omega value for one of the factors of the PSS-10 was slightly lower than the minimum acceptable value of 0.70 (Additional file 3). However, internal consistency was very poor for the PSS-4: Factor-2. Most of the previous studies have reported the Cronbach's alpha (0.74 to 0.91) for assessing internal consistency of the PSS, [2]. The item discrimination index, i.e., item-Factor correlations were all above 0.5 for both the PSS-10 as well as the PSS-4. This implies that item scores of the PSS had the ability to distinguish between high and low scoring individuals in the study population [23].

\section{Criterion-related validity: Convergent validity}

Stress conditions are closely associated with anxiety but they represent different psychological constructs [36], therefore previous studies have investigated the relationship between the PSS and measures of anxiety including the GAD-7 to establish its criterion validity [2]. However, noticeably this difference in the construct is perhaps accountable for the moderate level of correlation between the PSS and the GAD-7 scores in this study population of Ethiopian university students. Nevertheless, it can reasonably be concluded that the correlation between the PSS scores, i.e., PSS-10 total, PSS-4 total, PSS-10: Factor-1 and PSS-4: Factor-1 scores with the GAD-7 (Additional file 4, Table 4) favors the convergent validity of the PSS-10 and the PSS-4 in this population of Ethiopian university students. Previous studies have also supported the convergent validity of the PSS in different populations by assessing its correlation with measures of anxiety [21, 32-34]. Maroufizadeh et al. 2014 found a moderate association between the PSS and anxiety subscale of the Depression Anxiety Stress-21 scale in Persian asthmatic adults [33]. The convergent validity of the PSS had been supported by assessing correlations employing measures of anxiety-such as Spielberger Trait Anxiety Inventory in Spanish Americans [34], Hospital Anxiety and Depression Scale among American patients with systemic lupus erythematosus [21], and the GAD-7 among community-dwelling Hispanic Americans [32]. PSS Factor-2 did not correlate with these measures (Table 4) because it does not assess stress but coping strategy to stress conditions [20].

In summary, PSS-10 was found to have no major issues of the ceiling/floor effect, favorable factorial validity for 2-Factor model, internal consistency, item discrimination, and convergent validity among Ethiopian university 
students. However, psychometric properties were not adequate for the PSS-4 in the study population.

Limitations of the current study include a small number of female student's participants, non-assessment of diagnostic validity, and test-re-test reliability. The questionnaire was not administered in the first language of the respondents which may have limitations, but it is worth mentioning that the medium of instruction is English in the Ethiopian universities. The lower response rate among female participants was one of the important reasons that led to bias in gender representation in the final sample. Future works employing diagnostic clinical interview to explore the concurrent validity of the PSS in Ethiopians are needed. Nevertheless, there are notable merits of this study. We found adequate psychometric validation for the PSS-10 in a population which has limited access to expert medicine professionals and facilities. Many risk factors for behavioral problems are prevalent in Ethiopia. Therefore, the availability of a validated measure of stress is very important. The psychometric properties assessed in this study do support application of the PSS-10 to screen stress among Ethiopians.

\section{Conclusion}

The study provides support for the psychometric validation of the PSS-10 in the Ethiopian university students.

\section{Additional files}

Additional file 1: Item-Factor correlations, and Communality of the Perceived Stress Scale (PSS 10) in Ethiopian university students. Highlighted values: total survey sample $(n=562)$. Non-highlighted values: study sample $(n=386)$. (DOCX $15 \mathrm{~kb})$

Additional file 2: Fit statistics of the Perceived Stress Scale (PSS-10) in Ethiopian university students. Highlighted values: total survey sample (n $=562)$. Non-highlighted values: study sample $(n=386)$. (DOCX $13 \mathrm{~kb})$

Additional file 3: McDonald's Omega of the 2-Factor model of the PSS-10 in Ethiopian university students. Highlighted values: total survey sample (n $=562)$. Non-highlighted values: study sample $(n=386)(D O C X 11 \mathrm{~kb})$

Additional file 4: Convergent validity of the PSS-10 with Generalized Anxiety Disorder-7 scale in Ethiopian university students. Highlighted values: total survey sample $(n=562)$. Non-highlighted values: study sample $(n=386)$. (DOCX $12 \mathrm{~kb})$

Additional file 5: The file contains the data used in the psychometric analysis of the Perceived stress scale (PSS) in Ethiopian university students. The data file contain data related to participants' age, body mass index, athletic activity, grade at last examination, religion, gender, attendance, substance use(alcohol, smoking and khat use), PSS scores, generalized anxiety scale-7 total score. (DAT $25 \mathrm{~kb}$ )

\section{Abbreviations}

CFA: confirmatory factor analysis; CFI: Comparative Fit Index; DWLS: diagonally weighted least squares; GAD: Generalized anxiety disorder; KMO: Kaiser-Meyer-Olkin Test of Sampling Adequacy; PSS: Perceived stress scale; RMSEA: root mean square error of approximation; WRMR: weighted root mean square residual

\section{Acknowledgments}

We are grateful to the participants of the study. The authors would like to thank Deanship of Scientific Research at Majmaah University for supporting this work under Project Number No.1440-17. The dataset used in the study is a part of a multi-country research. Authors are grateful to the Deanship of Scientific Research, King Saud University (through Vice Deanship of Scientific Research Chairs) for providing the funding for the study carried in Saudi Arabia.

\section{Funding}

No funding was received for this study.

Availability of data and materials

All data file analyzed in this study is included in this published article (and its Additional file 5).

\section{Authors' contributions}

MDM: Concept development and study design, analysis and interpretation, manuscript preparation, critical revision of the manuscript, and approved the final version of the manuscript. MS: Data acquisition, interpretation, and approved the final version of the manuscript. SP: data acquisition, interpretation, and approved the final version of the manuscript. AA: Concept development, critical revision of the Manuscript, and approved the final version of the manuscript. SA: Data acquisition, interpretation, and approved the final version of the manuscript. SRP: Concept development, critical revision of the manuscript, and approved the final version of the manuscript. ASB: Concept development and study design, writing and critical revision of the manuscript, and approved the final version of the manuscript. All authors read and approved the final manuscript.

Ethics approval and consent to participate

The study was approved by the Human Institutional Ethics Committee Mizan-Tepi University, and a written informed consent was obtained from all participants.

All authors have approved the final draft.

Consent for publication

The participants provided informed consent to publish.

\section{Competing interests}

All the authors declare that they have no competing interests and no conflict of interest.

\section{Publisher's Note}

Springer Nature remains neutral with regard to jurisdictional claims in published maps and institutional affiliations.

\section{Author details}

${ }^{1}$ Department of Nursing, College of Applied Medical Sciences, Majmaah University, Al Majmaah 11952, Saudi Arabia. ²Department of Pharmacy, College of Medicine and Health Sciences, Mizan-Tepi University (Mizan Campus), Mizan-Aman, Ethiopia. ${ }^{3}$ Department of Biomedical Sciences, College of Medicine and Health Sciences, Mizan-Tepi University (Mizan Campus), Mizan-Aman, Teppi, Ethiopia. ${ }^{4}$ Rehabilitation Research Chair, College of Applied Medical Sciences, King Saud University, Riyadh, Saudi Arabia. ${ }^{5}$ The University Sleep Disorders Center, College of Medicine, King Saud University, Box 225503, Riyadh 11324, Saudi Arabia. ${ }^{6}$ National Plan for Science and Technology, College of Medicine, King Saud University, Riyadh, Saudi Arabia. ${ }^{7}$ Somnogen Canada Inc, College Street, Toronto, ON, Canada.

Received: 2 August 2018 Accepted: 6 December 2018 Published online: 09 January 2019

\section{References}

1. Lazarus RS, Folkman S. Stress, appraisal, and coping. New York: Springer Publishing Company; 1984

2. Lee EH. Review of the psychometric evidence of the perceived stress scale. Asian nursing research. 2012;6(4):121-7.

3. Cohen S, Williamson G. Perceived Stress in a Probability Sample of the United States. In: Spacapan S, Oskamp S, editors. The Social Psychology of 
Health: The Claremont Symposium on Applied Social Psychology. Newbury Park: SAGE Publications; 1988.

4. Cohen BE, Edmondson D, Kronish IM. State of the art review: depression, stress, anxiety, and cardiovascular disease. Am J Hypertens. 2015;28(11):1295-302.

5. Cohen S, Janicki-Deverts D, Miller GE. Psychological stress and disease. Jama. 2007:298(14):1685-7.

6. Lemma S, Gelaye B, Berhane Y, Worku A, Williams MA. Sleep quality and its psychological correlates among university students in Ethiopia: a crosssectional study. BMC psychiatry. 2012;12:237.

7. Bifftu BB, Dachew BA, Tiruneh BT, Birhan Tebeje N. Depression among people with epilepsy in Northwest Ethiopia: a cross-sectional institution based study. BMC research notes. 2015;8:585.

8. Tesfaye SH, Bune GT. Generalized psychological distress among HIV-infected patients enrolled in antiretroviral treatment in Dilla University hospital, Gedeo zone, Ethiopia. Glob Health Action. 2014;7(1):23882.

9. Salilih SZ, Abajobir AA. Work-related stress and associated factors among nurses working in public hospitals of Addis Ababa, Ethiopia: a crosssectional study. Workplace health \& safety. 2014;62(8):326-32.

10. Haileye A. Psychopathological correlates of child sexual abuse: the case of female students in Jimma zone, south West Ethiopia. Ethiopian journal of health sciences. 2013;23(1):32-8.

11. Salahuddin M, Maru TT, Kumalo A, Pandi-Perumal SR, Bahammam AS, Manzar MD. Validation of the Pittsburgh sleep quality index in community dwelling Ethiopian adults. Health Qual Life Outcomes. 2017;15(1):58.

12. Manzar MD, Salahuddin M, Maru TT, Dadi TL, Abiche MG, Abateneh DD, PandiPerumal SR, Bahammam AS. Sleep correlates of substance use in communitydwelling Ethiopian adults. Sleep \& breathing = Schlaf \& Atmung. 2017.

13. Manzar MD, Sony P, Salahuddin M, Kumalo A, Geneto M, Pandi-Perumal SR, Moscovitch A, BaHammam AS. Electrolyte imbalance and sleep problems during anti-retroviral therapy: an under-recognized problem. Sleep Sci. 2017;10(2):64-7.

14. Kebede D, Alem A, Mitike G, Enquselassie F, Berhane F, Abebe Y, Ayele R, Lemma W, Assefa T, Gebremichael T. Khat and alcohol use and risky sex behaviour among in-school and out-of-school youth in Ethiopia. BMC Public Health. 2005:5:109.

15. Maes K, Shifferaw S. Cycles of poverty, food insecurity, and psychosocial stress among Aids care volunteers in urban Ethiopia. Annals of anthropological practice. 2011;35(1):98-115.

16. Geibel S, Habtamu K, Mekonnen G, Jani N, Kay L, Shibru J, Bedilu L, Kalibala S. Reliability and validity of an interviewer-administered adaptation of the youth self-report for mental health screening of vulnerable young people in Ethiopia. PLoS One. 2016;11(2):e0147267.

17. Reda AA. Reliability and validity of the Ethiopian version of the hospital anxiety and depression scale (HADS) in HIV infected patients. PLoS One. 2011;6(1):e16049.

18. Hanlon C, Medhin G, Alem A, Araya M, Abdulahi A, Hughes M, Tesfaye M, Wondimagegn $\mathrm{D}$, Patel $\mathrm{V}$, Prince $\mathrm{M}$. Detecting perinatal common mental disorders in Ethiopia: validation of the self-reporting questionnaire and Edinburgh postnatal depression scale. J Affect Disord. 2008;108(3):251-62.

19. Tesfaye M, Hanlon C, Wondimagegn D, Alem A. Detecting postnatal common mental disorders in Addis Ababa, Ethiopia: validation of the Edinburgh postnatal depression scale and Kessler scales. J Affect Disord. 2010;122(1-2):102-8.

20. Cohen S, Kamarck T, Mermelstein R. A global measure of perceived stress. J Health Soc Behav. 1983;24(4):385-96.

21. Mills SD, Azizoddin D, Racaza GZ, Wallace DJ, Weisman MH, Nicassio PM. The psychometric properties of the perceived stress Scale-10 among patients with systemic lupus erythematosus. Lupus. 2017;26(11):1218-23.

22. Michaelides MP, Christodoulou A, Kkeli N, Karekla M, Panayiotou G. Structure factorielle de l'échelle de stress perçu et implications pour la cotation. Revue europeenne de psychologie appliquee. 2016;66(6):309-16.

23. Wang M, Batt K, Kessler C, Neff A, Iyer NN, Cooper DL, Kempton CL. Internal consistency and item-total correlation of patient-reported outcome instruments and hemophilia joint health score v2.1 in US adult people with hemophilia: results from the pain, functional impairment, and quality of life (P-FiQ) study. Patient Prefer Adherence. 2017;11:1831-9.

24. Spitzer RL, Kroenke K, Williams JB, Lowe B. A brief measure for assessing generalized anxiety disorder: the GAD-7. Arch Intern Med. 2006;166(10):1092-7.

25. Plummer F, Manea L, Trepel D, McMillan D. Screening for anxiety disorders with the GAD-7 and GAD-2: a systematic review and diagnostic metaanalysis. Gen Hosp Psychiatry. 2016;39:24-31.
26. Jaccard J, Wan C. LISREL approaches to interaction effects in multiple regression. Thousand Oaks: SAGE publications; 1996.

27. Manzar MD, BaHammam AS, Hameed UA, Spence DW, Pandi-Perumal SR, Moscovitch A, Streiner DL. Dimensionality of the Pittsburgh sleep quality index: a systematic review. Health Qual Life Outcomes. 2018;16(1):89.

28. Lim CR, Harris K, Dawson J, Beard DJ, Fitzpatrick R, Price AJ. Floor and ceiling effects in the OHS: an analysis of the NHS PROMs data set. BMJ Open. 2015;5(7):e007765.

29. Field AP. Discovering statistics using SPSS for windows: advanced techniques for the beginner. Thousand Oaks: Sage publications; 2000.

30. Child D. The essentials of factor analysis, 3rd edn. New York: Continuum International Publishing Group; 2006.

31. Wu SM, Amtmann D. Psychometric evaluation of the perceived stress scale in multiple sclerosis: International Scholarly Research Notices. ISRN Rehabil. 2013:2013:9. https://doi.org/10.1155/2013/608356.

32. Baik SH, Fox RS, Mills SD, Roesch SC, Sadler GR, Klonoff EA, Malcarne VL. Reliability and validity of the perceived stress Scale-10 in Hispanic Americans with English or Spanish language preference. J Health Psychol. 2017:1359105316684938.

33. Maroufizadeh S, Zareiyan A, Sigari N. Reliability and validity of Persian version of perceived stress scale (PSS-10) in adults with asthma. Archives of Iranian medicine. 2014;17(5):361-5.

34. Perera MJ, Brintz CE, Birnbaum-Weitzman O, Penedo FJ, Gallo LC, Gonzalez P, Gouskova N, Isasi CR, Navas-Nacher EL, Perreira KM, et al. Factor structure of the perceived stress Scale-10 (PSS) across English and Spanish language responders in the HCHS/SOL sociocultural ancillary study. Psychol Assess. 2017;29(3):320-8.

35. Örücü MÇ, Demir A. Psychometric evaluation of perceived stress scale for Turkish university students. Stress Health. 2009;25:103-9.

36. Bergdahl J, Bergdahl M: Perceived stress in adults: Prevalence and association of depression, anxiety and medication in a Swedish population, vol. 18; 2002.

\section{Ready to submit your research? Choose BMC and benefit from:}

- fast, convenient online submission

- thorough peer review by experienced researchers in your field

- rapid publication on acceptance

- support for research data, including large and complex data types

- gold Open Access which fosters wider collaboration and increased citations

- maximum visibility for your research: over $100 \mathrm{M}$ website views per year

At BMC, research is always in progress.

Learn more biomedcentral.com/submissions 